\title{
ANALISIS PENGARUH KUALITAS PRODUK, HARGA, KUALITAS PELAYANAN, DAN PROMOSI TERHADAP KEPUASAN KONSUMEN PADA TOKO KUE XYZ DI JAKARTA
}

\author{
Sylvia Permata Sari \\ Program Studi Magister Manajemen Universitas Tarumanagara \\ Sylviapesylviape@yahoo.com
}

\begin{abstract}
The purpose of this research is to find out the variables that affect the customer satisfaction, this research is conducted in order to find out whether quality of product, price, quality of service, and promotion influence the customer satisfaction at xyz cake store in jakarta . analysis tool used to measure the influence of the elements mentioned above are multiple linear regression. Based on the analysis, it can be concluded that simultaneously the variable of product (X1), quality of service (X2), price (X3), and promotion (X4) influence the customer satisfaction (Y). it is also consluded that partially (individual)The quality of product, price, quality of service, and promotion influence the customer satisfaction. the result shows that quality of product and quality of service have the most impact significantly on customer satisfaction of cake product at xyz cake store.
\end{abstract}

Keywords: Customer Satisfaction, Product Quality, Service Quality, Price, Promotion.

\section{Latar Belakang}

Pengaruh perkembangan zaman yang semakin pesat membuat setiap pemilik usaha untuk senantiasa selalu melakukan riset dan pengembangan untuk meningkatkan kepuasan pelanggan yang membantu mempertahankan konsumen yang loyal. Untuk mendapatkan hasil yang maksimal, maka perusahaan harus memberikan nilai kepuasan terhadap pelayanan dengan harga yang bersaing dan mutu produk yang berkualitas.

Seiring dengan semakin banyaknya pelaku usaha yang bersaing untuk memenuhi kebutuhan dan keinginan konsumen, maka sangat perlu diperhatikan oleh para pelaku usaha bagaimana untuk menciptakan keunikan dari segi produk yang ditawarkan untuk dapat memberikan kepuasan kepada konsumen.

Kepuasan pelanggan merupakan hal yang harus diutamakan oleh perusahaan demi keberlangsungan usahanya. Untuk memenuhi kepuasan pelanggan, toko kue XYZ selalu memperhatikan faktor-faktor bauran pemasaran seperti kualitas produk, harga, dan kualitas pelayanan yang di tawarkan agar dapat berkualitas. Menyadari akan peranan pelanggan dan pengaruh kepuasan pelanggan, toko kue XYZ berupaya mencari cara yang dapat menciptakan kepuasan pelanggannya. Oleh karena itu toko kue XYZ dituntut secara terusmenerus untuk memperhatikan keunikan karakter kue dan rasa melalui kualitas produk, harga dan kualitas pelayanan agar dapat memberikan kepuasan kepada penggunanya.

Hal ini juga ini dianggap penting oleh toko kue XYZ sehingga perlu dievaluasi kembali tentang seberapa besar pengaruhnya terhadap para pelanggan dan sebagai dasar dalam mencapai kemajuan usaha.

Menurut Fauziah Bella Dinna dan Enggal Sriwardiningsih (2015) terdapat Kontribusi yang signifikan antara kualitas produk dan kualitas pelayanan terhadap kepuasan konsumen secara simultan dan partial.

Penelitian ini bertujuan untuk :

1. Mengetahui besarnya pengaruh kualitas produk terhadap kepuasan konsumen pada toko kue XYZ Jakarta.

2. Mengetahui besarnya pengaruh kualitas layanan terhadap kepuasan konsumen pada toko kue XYZ Jakarta. 
3. Mengetahui besarnya pengaruh harga terhadap kepuasan konsumen pada toko kue XYZ Jakarta.

4. Mengetahui besarnya pengaruh Promosi terhadap kepuasan konsumen pada toko kue XYZ Jakarta.

Berdasarkan uraian diatas, maka yang menjadi rumusan masalah dalam penelitian ini adalah :

1. Apakah kualitas produk berpengaruh terhadap kepuasan konsumen

2. Apakah harga berpengaruh terhadap kepuasan konsumen

3. Apakah kualitas pelayanan berpengaruh terhadap kepuasan konsumen

4. Apakah Promosi berpengaruh terhadap kepuasan konsumen

\section{Kajian Teori}

Kepuasan Konsumen (Customer Satisfaction). Menurut Kotler dan Keller (2016:153) mengatakan bahwa kepuasan (satisfaction) adalah perasaan senang atau kecewa yang timbul karena membandingkan kinerja yang di persepsikan produk atau hasil terhadap ekspetasi mereka. Jika kinerja gagal memenuhi ekspetasi, pelanggan akan tidak merasa puas. Jika kinerja sesuai dengan ekspetasi, maka konsumen akan merasa puas. Faktor-faktor yang mempengaruhi kepuasan konsumen mengatakan bahwa kepuasan konsumen sangat bergantung kepada persepsi dan harapan konsumen.

Kualitas Produk (Quality Of Product). Kualitas merupakan faktor dasar yang mempengaruhi konsumen dalam memilih berbagai jenis produk dan jasa yang berkembang pesat pada saat ini. Kualitas produk mempunyai hubungan yang sangat erat dengan kepuasan pelanggan karena kualitas dari suatu produk mempunyai nilai dari kemampuan produk itu sendiri untuk menciptakan kepuasan pelanggan. (Ransulangi et al., 2015). Dalam hal ini, kue-kue berbentuk unik dengan cita rasa yang berbeda merupakan suatu kualitas produk yang ditawarkan oleh toko kue XYZ, hal ini yang membedakan toko kue XYZ dengan penjual kue lainnya.

Kualitas Pelayanan (Quality Of Service). Kualitas pelayanan merupakan tingkat keunggulan yang diharapkan dan pengendalian atas tingkat keunggulan tersebut untuk memenuhi keinginan konsumen. Cara untuk mempertahankan konsumen adalah memberikan jasa dengan kualitas pelayanan yang lebih tinggi dari pesaing secara konsisten dan memenuhi harapan pelanggan. Kualitas pelayanan yang baik akan meningkatkan kepuasan konsumen. Sebaliknya kualitas pelayanan yang buruk akan menurunkan kepuasan konsumen. Kualitas pelayanan dapat mempengaruhi kepuasan konsumen. (Gulla et al., 2015).

Harga (Price). Kesesuaian harga dengan manfaat Aspek penetapan harga yang dilakukan oleh produsen atau penjual yang sesuai dengan manfaat yang dapat di peroleh konsumen dari produk yang dibeli. (Stanton dalam Ofela dan Agustin 2016:4)

Promosi (Promotion). Promosi merupakan salah satu kegiatan pemasaran yang penting bagi perusahaan dalam mempertahankan kontinuitas serta meningkatkan kualitas penjualan, dan untuk meningkatkan kegiatan pemasaran terhadap barang atau jasa dari suatu perusahaan. Promosi merupakan suatu ungkapan dalam arti luas tentang kegiatan-kegiatan yang secara efektif dilakukan perusahaan untuk mendorong konsumen menggunakan produk atau jasa yang ditawarkan. (Gulla et al., 2015).

\section{Hipotesis Penelitian}

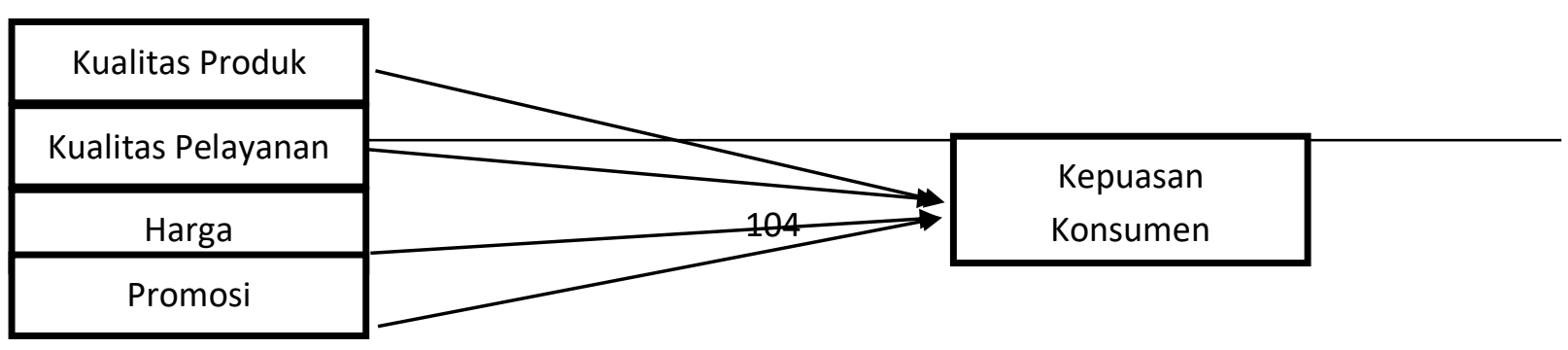




\section{Pengaruh kualitas produk terhadap kepuasan pelanggan}

Kualitas produk mempunyai hubungan yang sangat erat dengan kepuasan pelanggan karena kualitas dari suatu produk mempunyai nilai dari kemampuan produk itu sendiri untuk menciptakan kepuasan pelanggan. Oleh karena itu, semakin tinggi kualitas suatu produk maka akan meningkatkan kepuasan pelanggan.

Berdasarkan kajian teoritis, kajian empiris dan dasar logika, maka hipotesis alternatif yang diajukan dalam penelitian ini adalah sebagai berikut.

Ha1: Kualitas produk memiliki pengaruh positif yang signifikan terhadap kepuasan pelanggan.

\section{Pengaruh kualitas pelayanan terhadap kepuasan pelanggan}

faktor yang menentukan tingkat keberhasilan perusahaan adalah kemampuan perusahaan dalam memberikan kualitas pelayanan kepada konsumen yang dapat menciptakan kepuasan. Oleh karena itu semakin tinggi kualitas pelayanan maka akan meningkatkan kepuasan pelanggan.

Berdasarkan kajian teoritis, kajian empiris dan dasar logika, maka hipotesis alternatif yang diajukan dalam penelitian ini adalah sebagai berikut.

Ha2: Kualitas pelayanan memiliki pengaruh positif yang signifikan terhadap kepuasan pelanggan.

\section{Pengaruh harga terhadap kepuasan pelanggan}

Harga memiliki manfaat yang besar terhadap tingkat kepuasan konsumen karena dengan harga yang efisien sesuai dengan manfaat dari produk yang didapat maka konsumen akan merasa puas. Oleh karena itu semakin efisien suatu harga maka akan meningkatkan kepuasan pelanggan.

Ha3: Harga memiliki pengaruh positif yang signifikan terhadap kepuasan pelanggan.

4. Pengaruh promosi terhadap kepuasan pelanggan

Promosi merupakan suatu ungkapan dalam arti luas tentang kegiatan-kegiatan yang secara efektif dilakukan perusahaan untuk mendorong konsumen menggunakan produk atau jasa yang ditawarkan dan dapat menimbulkan kepuasan pelanggan karena pelanggan dapat mengetahui produk apa yang dibutuhkan lewat pengiklanan tersebut. Oleh karena itu semakin tinggi tingkat promosi maka akan meningkatkan kepuasan pelanggan.

Ha4: Promosi memiliki pengaruh positif yang signifikan terhadap kepuasan pelanggan

\section{Metodologi Penelitian}

Dalam penelitian ini, penulis ingin meneliti hubungan atara variabel bebas (X1) yaitu kualitas produk, (X2) yaitu harga, (X3) yaitu kualitas pelayanan, (X4) yaitu promosi dengan variabel terkait $(\mathrm{Y})$ yaitu kepuasan pelanggan yang terjadi di toko kue XYZ.

Populasi dalam penelitian ini adalah setiap orang yang pernah membeli dan mengkonsumsi produk kue di toko kue XYZ jakarta sebanyak 240. Adapun populasi ditentukan dengan kriteria sebagai berikut :

1. Mengetahui adanya berbagai macam jenis produk kue di toko kue XYZ. 
2. Pernah membeli dan mengkonsumsi produk kue di toko kue XYZ Jakarta dalam 3 bulan terakhir.

Berdasarkan uraian diatas, penelitian ini menggunakan teknik judgement sampling ( Penarikan sampel berdasarkan penilaian ) dengan kriteria sampel yang digunakan adalah pembeli kue di toko kue XYZ Jakarta yang mengetahui adanya berbagai macam jenis produk kue di toko kue XYZ dan yang pernah membeli atau mengkonsumsi produk kue di toko kue XYZ Jakarta dalam 3 bulan terakhir. Proses pengolahan data dalam penelitian ini memanfaatkan beberapa software yang dapat membantu penelitian dengan alas an efisien dan efektifitas penelitian. Penggunaan Microsoft Excel 2010 sangat membantu dalam melakukan tabulasi data hasil jawaban responden, sedangkan Statistical Product for Service Solution (SPSS) versi 20.0 sangat membantu dalam mengolah data hang sebelumnya berbentuk tabulasi sederhana. Pengolahan data menggunakan SPSS versi 20.0 meliputi pengolahan data identitas responden dan analisa data.

Penentuan jumlah sampel dalam penelitian ini menggunakan rumus Slovin (Sugiyono, $2013: 57$ ) sebagai berikut:

Dimana:

$$
n=\frac{N}{N \cdot e^{2}+1}
$$

$\mathrm{n}=$ jumlah sampel

$\mathrm{N}=$ jumlah populas

$\mathrm{e}^{2}=$ nilai toleransi sebesar $0,05^{2}$

maka $n=150$

\section{Hasil Uji Statistik}

Berdasarkan perhitungan SPSS seluruh butir pernyataan pada variabel bebas adalah valid, karena nilai $r_{\text {hitung }}$ dari seluruh pernyataan yang ada menunjukan angka $>$ dari nilai $r_{\text {tabel }}(0,200)$.

Nilai Cronbach's Alpha sebesar 0,961 untuk kualitas produk, 0,905 untuk kualitas pelayanan, 0,858 untuk harga, 0,876 untuk promosi. Berarti Cronbach's Alpha > 0,6 yang menunjukkan semua pernyataan untuk variabel bebas $(\mathrm{X} 1, \mathrm{X} 2, \mathrm{X} 3, \mathrm{X} 4)$ adalah reliabel.

Berdasarkan hasil analisis regrensi berganda dengan SPSS ini diperoleh rumus persamaan regresi sebagai berikut:

$$
\mathrm{Y}=1,497+0.111(\mathrm{X} 1)+0,290(\mathrm{X} 2)+0,120(\mathrm{X} 3)+0,277(\mathrm{X} 4)+\mathrm{e}
$$

a. Konstanta sebesar 1,497 artinya jika Kualitas Produk (X1), Kualitas Layanan (X2), Harga (X3), dan Promosi (X4) nilainya adalah 0, maka Kepuasan pelanggan nilainya adalah 1,497 dengan asumsi variabel - variabel lainnya dianggap tetap.

b. Koefisien varabel X1 (Kualitas Produk) diperoleh sebesar 0,111 dengan tanda positif artinya, jika varianel independen nilainya tetap dan Kualitas Produk mengalami kenaikan 1, maka Kepuasan Pelanggan (Y) akan mengalami kenaikan sebesar 0,111. Jadi semakin baik Kualitas Produk yang digunakan maka semakin naik Kepuasan Pelanggan.

c. Koefisien variabel X2 (Kualitas Layanan) diperoleh sebesar 0,290 dengan tanda positif artinya, jika variabel independen nilainya tetap dan Kualitas Layanan mengalami kenaikan 1, maka Kepuasan Pelanggan (Y) akan mengalami kenaikan sebesar 0,290. Jadi semakin baik Kualitas Pellayanan maka semakin naik Kepuasan Pelanggan.

d. Koefisien variabel X3 (Harga) diperoleh sebesar 0,120 dengan tanda positif artinya, jika variabel independen nilainya tetap dan Harga mengalami kenaikan 1, maka 
Kepuasan Pelanggan (Y) akan mengalami kenaikan sebesar 0,120. Jadi semakin sesua harga maka semakin naik Kepuasan Pelanggan.

e. Koefisien variabel X4 (Promosi) diperoleh sebesar 0,277 dengan tanda positif artinya, jika variabel independen nilainya tetap dan Harga mengalami kenaikan 1, maka Kepuasan Pelanggan (Y) akan mengalami kenaikan sebesar 0,277.

Uji statistik $\mathrm{T}$ pada dasarnya menunjukan seberapa jauh pengaruh satu variabel independen secara individual dalam menerangkan variabel dependen.

1. Jika nilai signifikan $<0,05$ maka variabel independen berpengaruh secara signifikan terhadap variabel dependen sehingga hipotesis alternative (Ha) diterima.

2. Jika nilai signifikan $>0,05$ maka variabel independen tidak berpengaruh secara signifikan terhadap variabel dependen sehingga hipotesis alternative (Ha) tidak diterima.

$\mathrm{t}$-tabel $\alpha=0,05, \mathrm{df}=\mathrm{n}-1=150-1=149$ maka diperoleh $\mathrm{t}$-tabel adalah = 1,96 :

1. Variabel Kualitas Produk (X1)

Hasil pengujian regresi variabel Kualitas Produk terhadap Kepuasan Pelanggan seperti terlihat pada table 4.30 menunjukan nilai sig 0,000 . Nilai sig lebih kecil dari nilai probabilitas 0,05 dan t- hitung 6,359 lebih besar dari t-tabel 1,96 maka, $\mathrm{H}_{\mathrm{a}}$ diterima dan $\mathrm{H}_{0}$ ditolak, hal tersebut berarti, variabel independen Kualitas Produk (X1) secara parsial signifikan mempengaruhi variabel dependen Kepuasan Pelanggan (Y).

2. Variabel Kualitas Layanan (X2)

Hasil pengujian regresi variabel Kualitas Layanan terhadap Kepuasan Pelanggan seperti terlihat pada table 4.30 menunjukan nilai sig 0,000. Nilai sig lebih kecil dari nilai probabilitas 0,05 dan t- hitung 4,105 lebih besar dari t-tabel 1,96 maka, $\mathrm{H}_{\mathrm{a}}$ diterima dan $\mathrm{H}_{0}$ ditolak, hal tersebut berarti, variabel independen Kualitas Layanan (X2) secara parsial signifikan mempengaruhi variabel dependen Kepuasan Pelanggan (Y).

3. Variabel Harga (X3)

Hasil pengujian regresi variabel Kualitas Produk terhadap Kepuasan Pelanggan seperti terlihat pada table 4.30 menunjukan nilai sig 0,000. Nilai sig lebih kecil dari nilai probabilitas 0,05 dan t- hitung 9,079 lebih besar dari t-tabel 1,96 maka, $\mathrm{H}_{\mathrm{a}}$ diterima dan $\mathrm{H}_{0}$ ditolak, hal tersebut berarti, variabel independen Harga (X3) secara parsial signifikan mempengaruhi variabel dependen Kepuasan Pelanggan (Y).

4. Variabel Promosi (X4)

Hasil pengujian regresi variabel Kualitas Produk terhadap Kepuasan Pelanggan seperti terlihat pada table 4.30 menunjukan nilai sig 0,000. Nilai sig lebih kecil dari nilai probabilitas 0,05 dan t- hitung 8,208 lebih besar dari t-tabel 1,96 maka, $\mathrm{H}_{\mathrm{a}}$ diterima dan $\mathrm{H}_{0}$ ditolak, hal tersebut berarti, variabel independen Promosi (X4) secara parsial signifikan mempengaruhi variabel dependen Kepuasan Pelanggan (Y).

Hal ini selaras dengan penelitian : Moha dan Loindong (2016). 
Coefficients $^{\mathrm{a}}$

\begin{tabular}{|c|c|c|c|c|c|c|}
\hline \multirow{2}{*}{\multicolumn{2}{|c|}{ Model }} & \multicolumn{2}{|c|}{$\begin{array}{l}\text { Unstandardized } \\
\text { Coefficients }\end{array}$} & $\begin{array}{l}\text { Standardized } \\
\text { Coefficients }\end{array}$ & \multirow[t]{2}{*}{$\mathrm{t}$} & \multirow[t]{2}{*}{ Sig. } \\
\hline & & B & Std. Error & Beta & & \\
\hline \multirow{5}{*}{1} & (Constant) & 1.497 & .316 & & 4.744 & .000 \\
\hline & Kualitas Produk & .111 & .017 & .265 & 6.359 & .000 \\
\hline & Harga & .290 & .032 & .345 & 9.079 & .000 \\
\hline & $\begin{array}{l}\text { Kualitas } \\
\text { Layanan }\end{array}$ & .120 & .029 & .170 & 4.105 & .000 \\
\hline & Promosi & .277 & .034 & .308 & 8.208 & .000 \\
\hline
\end{tabular}

\section{Coefficients $^{\mathbf{a}}$}

\begin{tabular}{|l|l|l|}
\hline Model & \multicolumn{2}{|l|}{ Collinearity Statistics } \\
\cline { 2 - 3 } & Tolerance & VIF \\
\hline (Constant) & & \\
Kualitas Produk & .350 & 2.859 \\
Harga & .421 & 2.377 \\
Kualitas Layanan & .356 & 2.810 \\
Promosi & .430 & 2.323 \\
\hline
\end{tabular}


ANOVA ${ }^{\mathrm{a}}$

\begin{tabular}{|rl|r|r|r|r|r|}
\hline \multicolumn{2}{|l|}{ Model } & \multicolumn{1}{|c|}{$\begin{array}{c}\text { Sum of } \\
\text { Squares }\end{array}$} & \multicolumn{1}{c|}{ df } & $\begin{array}{c}\text { Mean } \\
\text { Square }\end{array}$ & F & Sig. \\
\hline \multirow{2}{*}{1} & Regression & 1105.524 & 4 & 276.381 & 375.588 & $.000^{\mathrm{b}}$ \\
& Residual & 106.700 & 145 & .736 & & \\
& Total & 1212.224 & 149 & & & \\
\hline
\end{tabular}

a. Dependent Variable: Kepuasan Pelanggan

b. Predictors: (Constant), Promosi, Harga, Kualitas Layanan, Kualitas Produk

Dari uraian di atas maka dapat diinterpretasikan sebagai berikut, dimana ftabel $\alpha=0,05, \mathrm{df} 2=\mathrm{n}-\mathrm{k}=150-5=145, \mathrm{df} 1=\mathrm{k}-1=5-1=4$, maka diperoleh $\mathrm{f}$-tabel sebesar 2,21 :

Nilai f-hitung sebesar 375,588 dengan nilai sig. sebesar 0,000

- $\quad$ Nilai f-hitung sebesar 375,588 > f-tabel 2,21 maka menolak $\mathrm{H}_{0}$, menerima $\mathrm{H}_{\mathrm{a}}$

- $\quad$ Sig $0,000<0,05$ maka, menolak $\mathrm{H}_{0}$, menerima $\mathrm{H}_{\mathrm{a}}$.

Berdasarkan data diatas maka, variabel independen yaitu Kualitas Produk (X1), Kualitas Layanan (X2), Harga (X3), Promosi (X4) berpengaruh dan signifikan terhadap varibael dependen Kepuasan Pelanggan (Y)

Hasil perhitungan nilai $\mathrm{F}$ ini selaras dengan penelitian : Gulla et al. (2015), Ofela (2016), Moha dan Loindong (2016), Ransulangi et al., (2015), Haily dan Yanti (2016).

Dependent Variable: Kepuasan Pelanggan

\section{Model Summary}

\begin{tabular}{|l|l|l|l|l|}
\hline $\begin{array}{l}\text { Mode } \\
1\end{array}$ & $\mathrm{R}$ & R Square & $\begin{array}{l}\text { Adjusted R } \\
\text { Square }\end{array}$ & $\begin{array}{l}\text { Std. Error of } \\
\text { the Estimate }\end{array}$ \\
\hline 1 & $.955^{\mathrm{a}}$ & .912 & .910 & .85782 \\
\hline
\end{tabular}

a. Predictors: (Constant), Promosi, Harga, Kualitas

Layanan, Kualitas Produk

Sumber : Hasil Pengolahan data SPSS 20.0,

$\mathbf{R}=\mathbf{0 , 9 5 5} \quad \mathbf{R}^{\mathbf{2}}=\mathbf{0 , 9 1 0}$

Berdasarkan table model summary angka $\mathrm{R}$ adalah 0,955 , yang memiliki arti bahwa semua hubungan variabel bebas $(\mathrm{X} 1, \mathrm{X} 2, \mathrm{X} 3, \mathrm{X} 4)$ pada variabel tetap $(\mathrm{Y})$ sangat kuat. Karena $\geq 0,6$.

Berdasarkan table 4.32 besarnya angka Adjusted $\mathrm{R}$ Square $\left(\mathrm{R}^{2}\right)$ adalah 0,910 angka tersebut dapat digunakan untuk melihat besarnya pengaruh Kualitas Produk (X1), Kualitas Layanan (X2), Harga (X3), dan Promosi (X4) terhadap Kepuasan Pelanggan (Y) dengan cara menghitung Koefisien Determinasi (KD) dengan menggunakan rumus sebagai berikut :

Koefisien Determinasi $=r^{2} \times 100 \%$

Koefisien Determinasi $=0,910 \times 100 \%$

Koefisien Determinasi $=91 \%$

Angka tersebut berarti bahwa sebesar 91\% Kepuasan Pelanggan dapat dijelaskan oleh variabel Kualitas Produk, Kualitas Layanan, Harga, dan Promosi, sedangkan sisanya 9\% dipengaruhi oleh variabel lain.

\section{Diskusi}

Hasil pengujian statistic dengan uji parsial menunjukkan bahwa variabel Kepuasan pelanggan (Y) dipengaruhi oleh variabel X1,X2,X3,X4. Dan variabel X1 dan X2 berpengaruh secara signifikan terhadap variabel kepuasan pelanggan $(\mathrm{Y})$. 


\section{Penutup.}

Berdasarkan hasil pengujian data dalam penelitian ini, menunjukkan bahwa variabel Kepuasan pelanggan (Y) dipengaruhi oleh variabel kualitas produk (X1), kualitas pelayanan (X2), harga (X3), dan promosi (X4) Hasil penelitian ini menunjukkan bahwa masih terdapat 9\% faktor lainnya yang berkontribusi mempengaruhi kepuasan pelanggan pada PT XYZ di Jakarta. Tujuannya adalah untuk mengetahui faktor independent lainnya yang lebih mempengaruhi kepuasan pelanggan di PT. XYZ di Jakarta.

\section{Saran}

Dengan memperhatikan hasil analisis dan pembahasan pada bab sebelumnya, maka saran penulis untuk diberikan kepada toko kue XYZ di Jakarta. Sehubungan Pengaruh Kualitas Produk, Kualitas Layanan, Harga, dan Promosi terhadap Kepuasan Pelanggan adalah sebagai berikut :

1. Kualitas Produk kue harus terus ditingkatkan lagi agar para konsumen semakin puas dengan kualitas produk ,Karena kualitas produk menjadi salah satu modal utama dalam menghadapi persaingan.

2. Kualitas Pelayanan yang diberikan oleh toko kue XYZ di Jakarta. Harus terus ditingkatkan lagi agar pelanggan menjadi semakin puas terhadap pelayanan yang diberikan toko kue XYZ di Jakarta.

3. Toko kue XYZ di Jakarta.harus lebih memperhatikan Kualitas Produk, Kualitas Layanan, Harga dan Promosi agar para Konsumen merasa semakin puas.

4. Menambah variabel, karena hasil penelitian ini menunjukkan bahwa masih terdapat 9\% faktor lainnya yang berkontribusi mempengaruhi kepuasan pelanggan pada PT XYZ di Jakarta.

\section{Daftar Referensi}

Kotler., Keller. (2016). Marketing Management (15 ${ }^{\text {th }}$ ed.), Pearson Education.

Sugiyono, (2012) Metode Penelitian Bisnis (MPB), Jakarta: Alfabeta.

Jurnal atau Penelitian :

Gulla., Oroh and Roring (2015, Maret). Analysis of price, promotion, and service quality toconsumer satisfaction on manado grace inn hotel. (Vol. 3, pp. 1313-1322).

Ofela., Agustin (2016, Januari). Pengaruh harga, kualitas produk, dan kualitas pelayanan terhadap kepuasan konsumen kebab kingabi. Sekolah Tinggi Ilmu Ekonomi Indonesia (STIESIA) Surabaya. Jurnal ilmu dan riset manajemen. (Vol.5, No 1).

Moha., Loindong (2016, Maret). The analysis of service quality on customer satisfaction and facilities in hotel yota manado. Fakultas Ekonomi dan Bisnis, Jurusan Manajemen Universitas Sam Ratulangi Manado. (Vol. 4, No. 1, pp.575-584).

Ransulangi., Mandey and Tumbuan (2015, September). The effect of product quality, price and servicescape to customer satisfaction of ocean 27 manado. Fakultas Ekonomi dan Bisnis Jurusan Manajemen Universitas Sam Ratulangi Manado. (Vol. 3, No. 3, pp. 839-848).

Fauziah Bella Dinna dan Enggal Sriwardiningsih (2015), Analisa Pengaruh Kualitas Produk Dan Kualitas Pelayanan Kepuasan Konsumen Yang Berdampak Pada Berdampak Pada Niat Pembelian Ulang Konsumen PT. Duta Esa Astuti. 
Haily dan Yanti (2016, Oktober). Pengaruh kualitas, harga, dan promosi terhadap kepuasan konsumen pada PT. Prima Tour dan Travel. (Vol.8, No. 2 pp. 13-23).

Internet :

http://www.google.com

http://www.scholar.google.co.id 


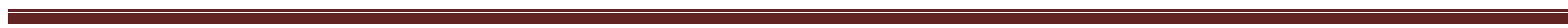
$\cdot$ 